\title{
Os desafios encontrados na Sistematização da Assistência de Enfermagem em instituições hospitalares brasileiras
}

\author{
Erika Fonseca Camargo Marsico, M.Sc.*, Sônia Elenilda da Silva**
}

*Enfermeira do setor de cardiologia e cirurgia vascular do Hospital Universitário Clementino Fraga Filho, Enfermeira da Unidade Coronariana do Hospital Municipal Souza Aguiar, *Especialista em Oncologia Clínica pela Universidade Gama Filho, Enfermeira do setor de clínica médica da Fundação Municipal Hospitalar de Macaé

\section{Resumo}

A Sistematização da Assistência de Enfermagem (SAE) é uma metodologia que caracteriza a prática do enfermeiro pela qual o mesmo, sistematicamente, aplica seus conhecimentos técnico-científicos com intervençóes individualizadas conforme a necessidade de assistência de cada paciente. O objetivo deste estudo é levantar através de revisão de literatura publicaçóes que abordem os desafios da implementação da SAE na prática assistencial. Foram consultados artigos indexados em bases de dados eletrônicas utilizando para critério de busca os descritores: processos de enfermagem e enfermagem. De 181 artigos encontrados, foram incluídos apenas 16. Dentre os principais fatores que dificultam a implantação da SAE estão: falta de conhecimento teórico sobre o processo de enfermagem, falta de conhecimento sobre a realização de exame físico e prescrição de enfermagem, sobrecarga de trabalho, insuficiência de recursos humanos, falta de tempo, de motivação, de comprometimento, resistência a mudanças e falta de credibilidade nas prescriçóes de enfermagem.

Palavras-chave: Enfermagem, processos de enfermagem.

\section{Abstract \\ The challenges faced in nursing care systematization in Brazilian hospitals}

Nursing Care Systematization (NCS) is a methodology that characterizes nursing practice model through which the nurses systematically applies their technical-scientific knowledge to individualize intervention according to the amount of patient's nursing care requirements. The objective of this study is to obtain, using literature review, published literature concerning challenges to implement NCS in clinical practice. The sources consulted were articles indexed in electronic databases using the following descriptors as search criteria: nursing process and nursing. Sixteen out of 181 articles found in the search were included. Among the main factors that hinder the implementation of the SNA are: lack of theoretical knowledge of nursing process, lack of knowledge about performing physical examination and prescription of nursing, workload, inadequate resources, lack of time, lack of motivation and commitment, resistance to change and lack of credibility in nursing prescriptions.

Key-words: Nursing, nursing process. 


\section{Resumen \\ Los desafíos encontrados en la sistematización de cuidados de enfermería en hospitales de Brasil}

La Sistematización de Cuidados de Enfermería (SCE) es una metodología que caracteriza la práctica del enfermero por la cual aplica sistemáticamente sus conocimientos técnico- científicos con intervenciones individualizadas de acuerdo con las necesidades particulares de cada paciente. El objetivo de este estudio es buscar, a través de una revisión de la literatura, publicaciones sobre los desafíos de la implementación de la SCE en la práctica clínica. Consultamos artículos indexados en bases de datos electrónicas, utilizando para criterio de búsqueda los descriptores: proceso de enfermería y enfermería. De los 181 estudios encontrados, sólo 16 fueron incluidos. Entre los principales factores que dificultan la implantación de la SCE están: la falta de conocimientos teóricos del proceso de enfermería, la falta de conocimiento sobre la realización de examen físico y la prescripción de enfermería, la sobrecarga de trabajo de enfermería, la falta de recursos humanos, falta de tiempo, de motivación, de comprometimiento, resistencia al cambio y la falta de credibilidad en las prescripciones de enfermería.

Palabras-clave: Enfermería, proceso de Enfermería.

\section{Introdução}

A Sistematização da Assistência de Enfermagem (SAE) configura-se, como uma metodologia para organizar e sistematizar o cuidado, tendo como objetivos: identificar as situaçóes de saúde-doença e as necessidades de cuidados de enfermagem, bem como apontar as intervençóes de promoção, prevenção, recuperação e reabilitação da saúde do paciente, família e comunidade [1].

É uma metodologia que caracteriza a prática profissional do enfermeiro através da qual o mesmo, sistematicamente, aplica seus conhecimentos técnico-científicos por meio de intervençóes individualizadas de enfermagem conforme a necessidade de assistência para cada paciente.

A SAE resume-se em cinco etapas que estão sobrepostas e inter-relacionadas, sendo elas: investigação (coleta de dados), diagnóstico, planejamento, implementação e avaliação [2]. Nesse sentido, trata-se de uma maneira sistemática e dinâmica de prestar cuidados de enfermagem de forma humanizada e holística que beneficia tanto o paciente, através de um atendimento individualizado, assim como os enfermeiros, mostrando-lhes a importância do processo de enfermagem [3].

A dinâmica da sistematização da assistência de enfermagem, através da sequência das suas fases que estão inter-relacionadas e interdependentes, baseadas no conhecimento científico do enfermeiro, identifica as necessidades do indivíduo como um todo e implementa uma intervenção através do cuidado centralizado nas necessidades do paciente [4].
Embora a maior parte dos enfermeiros tenha uma visão da necessidade e aplicabilidade da SAE, na sua realidade concreta, o processo de implantação, assim como a escolha de um referencial teórico e uma metodologia adequada constituem um grande desafio [5].

Em um estudo publicado em 2006 que aborda a produção do conhecimento sobre sistematizaçáo da assistência de enfermagem no Brasil, alegaçóes como falta de profissionais e área de conhecimento nova aparecem como justificativas para as dificuldades na implementação da SAE. Porém, não foram identificados trabalhos que discutissem de maneira mais ampla outros fatores que poderiam estar dificultando a implementação do processo nas diferentes instituições brasileiras [6].

Diante dessas consideraçóes, este trabalho de pesquisa tem por finalidade realizar uma revisão narrativa sobre a SAE, considerando a seguinte questão problema norteadora: Quais os principais desafios para a implementação da SAE na prática assistencial?

Com base nessa problemática, delimitou-se como objetivo geral deste estudo levantar através de revisão narrativa de literatura publicaçóes que abordem os desafios da implementação da sistematizaçáo da assistência de enfermagem na prática assistencial. O objetivo específico consiste em descrever as dificuldades para a implementação da SAE na prática assistencial.

A abordagem ao tema proposto encontra sua justificativa no fato de que a SAE constitui uma exigência para as instituiçóes de saúde públicas e privadas de todo o Brasil, de acordo com a resolução do Conselho Federal de Enfermagem: 
"O Processo de Enfermagem deve ser realizado, de modo deliberado e sistemático, em todos os ambientes, públicos ou privados, em que ocorre o cuidado profissional de Enfermagem (...) O Processo de Enfermagem deve estar baseado num suporte teórico que oriente a coleta de dados, o estabelecimento de diagnósticos de enfermagem e o planejamento das ações ou intervençóes de enfermagem; e que forneça a base para a avaliação dos resultados de enfermagem alcançados [7].”

A SAE é também uma orientação da lei do exercício profissional da enfermagem:

\footnotetext{
"Uma atividade privativa do enfermeiro, a qual utiliza método e estratégia científica das situaçôes de saúde-doença que subsidia as ações de assistência de enfermagem para que possam contribuir com a promoção, prevenção, recuperação e a reabilitação da saúde do indivíduo, família e comunidade [8]."
}

Também, a implantação da SAE se torna uma estratégia na organização da assistência de enfermagem nas instituiçôes, atendendo, assim, aos requisitos do Manual Brasileiro da Acreditação Hospitalar.

Dessa forma, busca-se com esta pesquisa contribuir para identificação de fatores que possam comprometer a implementaçáo da SAE na prática assistencial e despertar uma reflexão crítica acerca da importância dessa metodologia como instrumento de avaliaçáo dos pacientes. Nesse contexto, a sistematização oferece essa possibilidade, uma vez que enfermeiros identificam a presença de necessidades humanas básicas afetadas nos pacientes e assim conseguem prestar uma assistência planejada e fundamentada no conhecimento científico [9].

\section{Material e métodos}

Este estudo consiste numa revisão narrativa de literatura, que é um método de pesquisa utilizado para descrever e discutir o desenvolvimento ou o "estado da arte" de um determinado assunto, sob ponto de vista teórico ou contextual [10].

Realizou-se levantamento bibliográfico, durante os meses de abril a junho de 2011, de publicaçóes indexadas nas seguintes bases de dados eletrônicas: Base de dados de Enfermagem (BDENF), Literatura Latino-Americana e do Caribe em Ciências da Saúde (LILACS) e Scientific Eletronic Library Online (SCIELO), utilizando-se como descritores: enfermagem e processos de enfermagem.

Foram adotados como critérios de inclusão: artigos publicados em português; artigos na íntegra que retratassem a temática referente a dificuldades na implantação da SAE e artigos publicados e indexados nos referidos bancos de dados nos últimos dez anos. Adotou-se como critério de exclusão artigos que não foram encontrados na íntegra.

Das 181 referências encontradas, 45 foram excluídas por não estarem disponíveis na íntegra on-line; oito foram excluídas por estarem escritas na língua inglesa e cinco foram excluídas por terem sido publicadas há mais de 10 anos. Dos 123 artigos restantes, apenas 16 discutiam a questão dos desafios e dificuldades encontradas na implantação da SAE prática assistencial.

Para os artigos incluídos, foi preenchido um quadro para coleta de dados para cada um contendo informaçóes no que se refere a autores, ano de publicação, revista de publicação, objetivo, métodos e resultados. Os estudos foram organizados por ano de publicação e analisados criticamente por meio de leitura na íntegra, sendo estes transcritos em fichas bibliográficas, contendo a referência da obra e os pontos principais da mesma (fichamento). A partir dos dados oriundos do levantamento bibliográfico foi realizada a síntese das dificuldades apontadas e a sua discussão.

\section{Resultados}

O Quadro I demonstra a distribuição dos 16 artigos encontrados que fizeram parte da amostra e que discutem a questáo das dificuldades na implantação da SAE.

Dos 16 artigos selecionados, nove utilizaram como método a pesquisa qualitativa, um a pesquisa quantitativa, um a pesquisa quanti-qualitativa, três foram revisões de literatura, um utilizou o método retrospectivo de revisão de prontuário e um se referiu a um estudo de caso.

Dentre os artigos que publicaram pesquisas de campo, os quais totalizaram 13, quatro foram realizados no estado de São Paulo, quatro no Rio Grande do Sul, um em Sergipe, um em Piauí e um no estado do Rio de Janeiro. 
Quadro I - Produção científica sobre as dificuldades na implantação da Sistematização da Assistência de Enfermagem (SAE) no período de 2001 a 2010.

\begin{tabular}{|c|c|c|c|c|}
\hline Autores & $\begin{array}{l}\text { Revista e } \\
\text { ano de } \\
\text { publicação }\end{array}$ & Objetivo & Método & Resultados \\
\hline $\begin{array}{l}\text { Monte et } \\
\text { al. [11 } 1]\end{array}$ & $\begin{array}{l}\text { Acta Pau- } \\
\text { lista de en- } \\
\text { fermagem } \\
(2001)\end{array}$ & $\begin{array}{l}\text { Identificar as dificul- } \\
\text { dades existentes para } \\
\text { desenvolver e aprimorar } \\
\text { os processos de SAE } \\
\text { em hospitais gerais de } \\
\text { grande e extra porte do } \\
\text { município de São Paulo }\end{array}$ & $\begin{array}{l}\text { Estudo descritivo de aborda- } \\
\text { gem qualitativa, realizado } \\
\text { em } 18 \text { hospitais da rede pú- } \\
\text { blica e privada do município } \\
\text { de São Paulo. Participaram } \\
\text { da pesquisa } 18 \text { enfermeiros. } \\
\text { A coleta de dados foi rea- } \\
\text { lizada através de entrevista } \\
\text { semiestruturada. }\end{array}$ & $\begin{array}{l}\text { As dificuldades para implementa- } \\
\text { ção da SAE estão relacionadas a: } \\
\text { preparo inadequado de enfermeiros; } \\
\text { carência de pessoal de enfermagem } \\
\text { e falta de comprometimento, envol- } \\
\text { vimento e responsabilidade desses } \\
\text { profissionais. }\end{array}$ \\
\hline $\begin{array}{l}\text { Hermida } \\
\text { [12] }\end{array}$ & $\begin{array}{l}\text { Revista } \\
\text { Brasileira } \\
\text { de Enfer- } \\
\text { magem } \\
(2004)\end{array}$ & $\begin{array}{l}\text { Identificar as dificul- } \\
\text { dades encontradas } \\
\text { na implementação da } \\
\text { SAE e os fatores que } \\
\text { interferem prejudicando } \\
\text { sua implementação, } \\
\text { nos trabalhos nacionais } \\
\text { publicados nos últimos } \\
\text { cinco anos. }\end{array}$ & $\begin{array}{l}\text { Revisão de literatura utili- } \\
\text { zando as bases de dados } \\
\text { Medline, Lilacs e BDENF. }\end{array}$ & $\begin{array}{l}\text { Dentre os fatores que dificultam a } \\
\text { implantação do SAE estão: falta de } \\
\text { conhecimento sobre a realização do } \\
\text { exame físico; } \\
\text { dificuldades de identificar o diag- } \\
\text { nóstico de enfermagem por falta de } \\
\text { leitura; dificuldade de elaborar a } \\
\text { prescrição de enfermagem, de cum- } \\
\text { prir as prescrições; descontinuidade } \\
\text { da implementação da assistência } \\
\text { entre turnos; carência de pessoal de } \\
\text { enfermagem. }\end{array}$ \\
\hline $\begin{array}{l}\text { Pivotto et } \\
\text { al. [13] }\end{array}$ & $\begin{array}{l}\text { Cogitare } \\
(2004)\end{array}$ & $\begin{array}{l}\text { Identificar os motivos } \\
\text { da não realização da } \\
\text { prescrição de enferma- } \\
\text { gem nas unidades de } \\
\text { internação de um hospi- } \\
\text { tal universitário; apontar } \\
\text { possíveis alternativas } \\
\text { para o aprimoramento } \\
\text { das ações de enfer- } \\
\text { magem e estratégias } \\
\text { favoráveis a implan- } \\
\text { tação, implementação } \\
\text { e consolidação da } \\
\text { prescrição de cuidados } \\
\text { da enfermagem. }\end{array}$ & $\begin{array}{l}\text { Pesquisa exploratória } \\
\text { descritiva, de abordagem } \\
\text { qualitativa, realizada em um } \\
\text { Hospital Universitário com } \\
37 \text { enfermeiros. A coleta } \\
\text { de dados foi realizada por } \\
\text { meio de um questionário, } \\
\text { constituído de perguntas } \\
\text { fechadas e abertas. }\end{array}$ & $\begin{array}{l}\text { Os motivos apontados foram: } \\
\text { falta de credibilidade e a cultura } \\
\text { da desvalorização da prescrição de } \\
\text { enfermagem; a exiguidade do tem- } \\
\text { po, a carência de pessoal e o não } \\
\text { estabelecimento de prioridades na } \\
\text { realização e organização do trabalho } \\
\text { de enfermagem; percepções sobre } \\
\text { suas repercussões na organização do } \\
\text { trabalho, qualidade da assistência e } \\
\text { valorização profissional. }\end{array}$ \\
\hline $\begin{array}{l}\text { Andrade } \\
\text { e Vieira } \\
{[14]}\end{array}$ & $\begin{array}{l}\text { Revista } \\
\text { Brasileira } \\
\text { de Enfer- } \\
\text { magem } \\
(2005)\end{array}$ & $\begin{array}{l}\text { Identificar, na } \\
\text { percepção dos enfer- } \\
\text { meiros, os principais } \\
\text { problemas decorren- } \\
\text { tes da não utilização } \\
\text { de uma metodologia } \\
\text { assistencial no hospital } \\
\text { universitário. }\end{array}$ & $\begin{array}{l}\text { Estudo qualitativo descritivo } \\
\text { realizado em um hospital uni- } \\
\text { versitário. Utilizou-se questio- } \\
\text { nários abordando atividades, } \\
\text { percepção sobre Enferma- } \\
\text { gem e cliente, conhecimento } \\
\text { e aplicação do processo de } \\
\text { Enfermagem e problemas } \\
\text { decorrentes da assistência } \\
\text { não sistematizada. }\end{array}$ & $\begin{array}{l}\text { Os problemas mais } \\
\text { citados decorrentes da não sistemati- } \\
\text { zação da assistência foram: falta de } \\
\text { comprometimento, desorganização } \\
\text { do serviço e conflito de papéis. }\end{array}$ \\
\hline
\end{tabular}




\begin{tabular}{|c|c|c|c|c|}
\hline $\begin{array}{l}\text { Backes e } \\
\text { Schwartz } \\
{[5]}\end{array}$ & $\begin{array}{l}\text { Acta Scien- } \\
\text { tarium } \\
\text { Health } \\
(2005)\end{array}$ & $\begin{array}{l}\text { Relatar os principais } \\
\text { desafios e conquistas do } \\
\text { ponto de vista gerencial } \\
\text { no que tange à imple- } \\
\text { mentação da SAE }\end{array}$ & $\begin{array}{l}\text { O estudo adotou a meto- } \\
\text { dologia problematizadora } \\
\text { da realidade, baseada em } \\
\text { Paulo Freire. Participaram } \\
\text { da pesquisa } 40 \text { enfermeiros } \\
\text { de uma instituição de saúde } \\
\text { em Pelotas. }\end{array}$ & $\begin{array}{l}\text { As dificuldades apontadas foram: } \\
\text { deficiência de recursos humanos, } \\
\text { descrença e despreparo de muitos } \\
\text { profissionais. }\end{array}$ \\
\hline $\begin{array}{l}\text { Backes et } \\
\text { al. [3] }\end{array}$ & $\begin{array}{l}\text { Ciência, } \\
\text { Cuidado } \\
\text { e Saúde } \\
(2005)\end{array}$ & $\begin{array}{l}\text { Relatar as percepções } \\
\text { dos enfermeiros em re- } \\
\text { lação à implementação } \\
\text { da SAE. }\end{array}$ & $\begin{array}{l}\text { Estudo exploratório des- } \\
\text { critivo com delineamento } \\
\text { qualitativo. A pesquisa foi } \\
\text { desenvolvida em um hos- } \\
\text { pital filantrópico de gran- } \\
\text { de porte em Pelotas, Rio } \\
\text { Grande do Sul. Participaram } \\
\text { do estudo } 35 \text { enfermeiros. A } \\
\text { coleta de dados foi reali- } \\
\text { zada através de entrevista } \\
\text { semiestruturada. }\end{array}$ & $\begin{array}{l}\text { As principais } \\
\text { dificuldades encontradas na implan- } \\
\text { tação da SAE } \\
\text { apontaram problemas em relação } \\
\text { à sobrecarga de trabalho; desvios } \\
\text { da função; número insuficiente de } \\
\text { profissionais para o desempenho } \\
\text { da atividade; falta de instrumentali- } \\
\text { zação; descrença dos profissionais } \\
\text { quanto à implementação da SAE. }\end{array}$ \\
\hline $\begin{array}{l}\text { Reppetto } \\
\text { e Souza } \\
{[15]}\end{array}$ & $\begin{array}{l}\text { Revista } \\
\text { Brasileira } \\
\text { de Enfer- } \\
\text { magem } \\
(2005)\end{array}$ & $\begin{array}{l}\text { Identificar a realização } \\
\text { e o registro das etapas } \\
\text { da SAE pelo processo } \\
\text { de enfermagem. }\end{array}$ & $\begin{array}{l}\text { Estudo descritivo, de caráter } \\
\text { retrospectivo, realizado nas } \\
\text { unidades de internação } \\
\text { de Cardiologia, Doenças } \\
\text { Infecto-Parasitárias no } \\
\text { Adulto e Neurocirurgia, em } \\
\text { um hospital universitário da } \\
\text { cidade de São Paulo. }\end{array}$ & $\begin{array}{l}\text { Constatou-se como dificuldades que } \\
\text { existem na implementação da SAE: } \\
\text { excesso de atribuições da enfermei- } \\
\text { ra, falta de preparo para utilização } \\
\text { desse método de trabalho, falta de } \\
\text { recursos materiais para o cuidado, } \\
\text { resistência na utilização e não valori- } \\
\text { zação do método }\end{array}$ \\
\hline $\begin{array}{l}\text { França et } \\
\text { al. [16] }\end{array}$ & $\begin{array}{l}\text { Revista } \\
\text { Brasileira } \\
\text { de Enfer- } \\
\text { magem } \\
(2007)\end{array}$ & $\begin{array}{l}\text { Descrever a implemen- } \\
\text { tação do Diagnóstico de } \\
\text { Enfermagem } \\
\text { na UTI adultos; relatar } \\
\text { o aprendizado teórico- } \\
\text {-prático dos enfermeiros } \\
\text { acerca do diagnóstico; } \\
\text { identificar os dificulta- } \\
\text { dores que interferiram } \\
\text { na sua implementação. } \\
\end{array}$ & $\begin{array}{l}\text { Estudo exploratório des- } \\
\text { critivo com delineamento } \\
\text { qualitativo. A pesquisa foi } \\
\text { desenvolvida na UTI adulto } \\
\text { do Hospital Regional da Asa } \\
\text { Norte, Brasília. }\end{array}$ & $\begin{array}{l}\text { As dificuldades vivenciadas foram: } \\
\text { inadequação à rotina da unidade, } \\
\text { falta de tempo, insuficiência de } \\
\text { recursos humanos, impressos indis- } \\
\text { poníveis, resistência do enfermeiro } \\
\text { à utilização e desvalorização do } \\
\text { método. }\end{array}$ \\
\hline $\begin{array}{l}\text { Gonçalves } \\
\text { et al. [17] }\end{array}$ & $\begin{array}{l}\text { Revista } \\
\text { Escola } \\
\text { Anna Nery } \\
(2007)\end{array}$ & $\begin{array}{l}\text { Discutir aspectos } \\
\text { relativos ao projeto de } \\
\text { implantação da SAE em } \\
\text { uma maternidade públi- } \\
\text { ca, segundo a ótica de } \\
\text { discentes de enferma- } \\
\text { gem da UFPI. } \\
\end{array}$ & $\begin{array}{l}\text { Estudo qualitativo realizado } \\
\text { em uma maternidade públi- } \\
\text { ca em Teresina-PI. O instru- } \\
\text { mento de coleta de dados } \\
\text { constou de um formulário } \\
\text { contendo questões abertas. }\end{array}$ & $\begin{array}{l}\text { Fatores dificultadores para a imple- } \\
\text { mentação da SAE: falta de conhe- } \\
\text { cimento profissional; resistência da } \\
\text { equipe de saúde; dificuldade do } \\
\text { preenchimento dos formulários; difi- } \\
\text { culdade da realização da prescrição } \\
\text { de cuidados. }\end{array}$ \\
\hline $\begin{array}{l}\text { Vargas } \\
\text { e França } \\
{[18]}\end{array}$ & $\begin{array}{l}\text { Revista } \\
\text { Brasileira } \\
\text { de Enfer- } \\
\text { magem } \\
(2007)\end{array}$ & $\begin{array}{l}\text { Descrever a SAE a um } \\
\text { portador de cirrose } \\
\text { hepática e relatar as } \\
\text { dificuldades encontra- } \\
\text { das na implementação } \\
\text { dessa assistência. }\end{array}$ & $\begin{array}{l}\text { Estudo de caso desenvolvido } \\
\text { no Hospital Regional de } \\
\text { Ceilândia, Brasília. }\end{array}$ & $\begin{array}{l}\text { As dificuldades encontradas foram: } \\
\text { desinteresse de alguns membros da } \\
\text { equipe de enfermagem em contri- } \\
\text { buir com a sistemática, deficiência } \\
\text { de conhecimento e despreparo dos } \\
\text { profissionais para lidar com esse mé- } \\
\text { todo de trabalho, recursos materiais } \\
\text { e humanos insuficientes. }\end{array}$ \\
\hline
\end{tabular}




\begin{tabular}{|c|c|c|c|c|}
\hline $\begin{array}{l}\text { Takahashi } \\
\text { et al. [19] }\end{array}$ & $\begin{array}{l}\text { Acta Pau- } \\
\text { lista de En- } \\
\text { fermagem } \\
(2008)\end{array}$ & $\begin{array}{l}\text { Identificar as dificul- } \\
\text { dades e facilidades } \\
\text { mencionadas por en- } \\
\text { fermeiras na execução } \\
\text { das fases do processo } \\
\text { de enfermagem em seu } \\
\text { local de trabalho. }\end{array}$ & $\begin{array}{l}\text { Pesquisa de natureza } \\
\text { descritiva e exploratória } \\
\text { realizada no hospital-escola } \\
\text { da UNIFESP. Participaram } \\
\text { da pesquisa } 83 \text { enfermeiras. } \\
\text { O instrumento de coleta de } \\
\text { dados constou de dois ques- } \\
\text { tionários com um total de } \\
26 \text { perguntas estruturadas e } \\
\text { abertas. }\end{array}$ & $\begin{array}{l}\text { As dificuldades apontadas foram: } \\
\text { falta de conhecimento sobre a } \\
\text { realização do exame físico; dificul- } \\
\text { dades de identificar o diagnóstico } \\
\text { de enfermagem por falta de leitura; } \\
\text { dificuldade de elaborar a prescrição } \\
\text { de enfermagem. Os motivos atri- } \\
\text { buídos às dificuldades apontadas } \\
\text { foram: falta de conhecimento teórico } \\
\text { e prático para a execução das fases } \\
\text { do processo de enfermagem; falta de } \\
\text { tempo e de recursos. }\end{array}$ \\
\hline Felix [20] & $\begin{array}{l}\text { Arqui- } \\
\text { vos de } \\
\text { Ciências } \\
\text { da Saúde } \\
(2009)\end{array}$ & $\begin{array}{l}\text { Levantar as dificuldades } \\
\text { encontradas pelo en- } \\
\text { fermeiro na realização } \\
\text { da SAE na unidade de } \\
\text { pronto atendimento. }\end{array}$ & $\begin{array}{l}\text { Estudo de campo, descritivo, } \\
\text { transversal, quantitativo rea- } \\
\text { lizado na Unidade de Pronto } \\
\text { atendimento do Hospital } \\
\text { de Base de São José do Rio } \\
\text { Preto, São Paulo. Partici- } \\
\text { pantes: } 09 \text { enfermeiros. O } \\
\text { instrumento de coleta de } \\
\text { dados foi um questionário } \\
\text { semiestruturado composto } \\
\text { por } 20 \text { questões. }\end{array}$ & $\begin{array}{l}\text { Os desafios apontados foram alta } \\
\text { demanda de clientes, falta de tempo, } \\
\text { desconhecimento teórico, inade- } \\
\text { quação do instrumento, descrédito } \\
\text { e desvalorização da prescrição de } \\
\text { enfermagem pela equipe de enfer- } \\
\text { magem, resistência dos enfermeiros. }\end{array}$ \\
\hline $\begin{array}{l}\text { Tannure et } \\
\text { al. [21] }\end{array}$ & $\begin{array}{l}\text { Revista } \\
\text { Nursing } \\
\text { (2009) }\end{array}$ & $\begin{array}{l}\text { Descrever fatores que } \\
\text { dificultam a implan- } \\
\text { tação do processo de } \\
\text { enfermagem (PE) na } \\
\text { prática. }\end{array}$ & $\begin{array}{l}\text { Revisão de literatura na } \\
\text { base de dados Bireme. }\end{array}$ & $\begin{array}{l}\text { Foram identificados como fatores } \\
\text { que dificultam a sua implantação } \\
\text { na prática: déficit de conhecimento } \\
\text { e receio por parte de enfermeiros e } \\
\text { docentes, aplicação mecânica das } \\
\text { etapas do PE, pouca implicação dos } \\
\text { enfermeiros para a concretização do } \\
\text { método na prática, falta de instru- } \\
\text { mentos adequados para registro das } \\
\text { etapas do processo, ausência de } \\
\text { serviços de educação continuada nas } \\
\text { instituições e de políticas institucio- } \\
\text { nais favoráveis à implantação do PE. }\end{array}$ \\
\hline Luiz [22] & $\begin{array}{l}\text { Revista } \\
\text { Eletrônica } \\
\text { de Enfer- } \\
\text { magem } \\
(2010)\end{array}$ & $\begin{array}{l}\text { Identificar as facilida- } \\
\text { des e dificuldades da } \\
\text { implantação da SAE, na } \\
\text { percepção da equipe de } \\
\text { enfermagem. }\end{array}$ & $\begin{array}{l}\text { Estudo descritivo de aborda- } \\
\text { gem qualitativa, realizado } \\
\text { em um hospital de ensino } \\
\text { no Rio Grande do Sul. } \\
\text { Participaram da pesquisa } 11 \\
\text { técnicos em enfermagem e } \\
\text { cinco enfermeiros. A coleta } \\
\text { de dados foi realizada atra- } \\
\text { vés de entrevista semiestru- } \\
\text { turada. }\end{array}$ & $\begin{array}{l}\text { As dificuldades apontadas foram: } \\
\text { falta de recursos materiais e huma- } \\
\text { nos, falta de informatização, falta de } \\
\text { tempo, falta de conhecimento teórico } \\
\text { na temática, falta de conhecimen- } \\
\text { to teórico dos profissionais com a } \\
\text { operacionalização do processo de } \\
\text { enfermagem, resistência e desmoti- } \\
\text { vação. }\end{array}$ \\
\hline
\end{tabular}




\begin{tabular}{|c|c|c|c|c|}
\hline $\begin{array}{l}\text { Remizoski } \\
\text { et al. [23] }\end{array}$ & $\begin{array}{l}\text { Cadernos } \\
\text { da Escola } \\
\text { de Saúde } \\
(2010)\end{array}$ & $\begin{array}{l}\text { Identificar nas publi- } \\
\text { cações sobre SAE, os } \\
\text { principais fatores que } \\
\text { dificultam sua implan- } \\
\text { tação na prática do } \\
\text { enfermeiro. }\end{array}$ & $\begin{array}{l}\text { Revisão de literatura uti- } \\
\text { lizando a base de dados } \\
\text { BDENF, com produções } \\
\text { científicas sobre SAE pu- } \\
\text { blicadas nos últimos nove } \\
\text { anos. }\end{array}$ & $\begin{array}{l}\text { Dentre os principais fatores que } \\
\text { dificultam a implantação do SAE } \\
\text { estão falta de conhecimento sobre } \\
\text { a realização do exame físico, falta } \\
\text { de treinamento sobre o tema nas } \\
\text { instituições de saúde, falta de registro } \\
\text { adequado da assistência de enfer- } \\
\text { magem, conflito de papéis, dificulda- } \\
\text { de de aceitação de mudanças, falta } \\
\text { de credibilidade nas prescrições de } \\
\text { enfermagem, carência de pessoal e } \\
\text { falta de estabelecimento de priorida- } \\
\text { des organizacionais. }\end{array}$ \\
\hline $\begin{array}{l}\text { Silva e } \\
\text { Moreira } \\
{[24]}\end{array}$ & $\begin{array}{l}\text { Revista } \\
\text { Eletrônica } \\
\text { de Enfer- } \\
\text { magem } \\
(2010)\end{array}$ & $\begin{array}{l}\text { Analisar os fatores inter- } \\
\text { venientes no processo } \\
\text { de implantação da SAE } \\
\text { referidos por enfermei- } \\
\text { ros. }\end{array}$ & $\begin{array}{l}\text { Estudo descritivo, de } \\
\text { abordagem qualitativa. A } \\
\text { pesquisa foi realizada na } \\
\text { unidade de internação de } \\
\text { um hospital especializado } \\
\text { em cuidados paliativos na } \\
\text { oncologia, localizado no } \\
\text { município do Rio de Janeiro. } \\
\text { Participaram } 8 \text { enfermei- } \\
\text { ras. A técnica de coleta de } \\
\text { dados utilizada foi o grupo } \\
\text { focal. }\end{array}$ & $\begin{array}{l}\text { Foram apontados como fatores que } \\
\text { interferem na implantação da SAE o } \\
\text { déficit de recursos humanos em en- } \\
\text { fermagem, a falta de conhecimento } \\
\text { em relação à temática e aos modelos } \\
\text { teóricos para a sistematização do } \\
\text { cuidado, não comprometimento e } \\
\text { falta de adesão de todos os profissio- } \\
\text { nais envolvidos no processo. }\end{array}$ \\
\hline
\end{tabular}

\section{Discussão}

A Sistematização da Assistência de Enfermagem (SAE), instrumento privativo do processo de trabalho do enfermeiro, configura-se como uma metodologia para organizar e sistematizar o cuidado, sendo composta pelas etapas do processo de enfermagem: o histórico, o diagnóstico de enfermagem, o planejamento e a avaliação de enfermagem.

Como apontam Silva et al. [25], "trata-se de uma maneira sistemática e dinâmica de prestar cuidados de enfermagem de forma humanizada e holística" [2]. Bittar et al. acrescentam que "incorporar a SAE é uma forma de tornar a enfermagem mais científica, promovendo um cuidar de enfermagem humanizado, contínuo, mais justo e com qualidade para o paciente/cliente".

A SAE é uma exigência legal imposta pela Resolução do COFEN no 272/2002, que determina sua implementação em todas as unidades de saúde. Entretanto, essa Resolução não foi suficiente para a implantação da SAE, já que muitas dificuldades ainda são encontradas para a implantação e implementação desta metodologia assistencial [26].

A partir da análise dos artigos foi possível veri- ficar a existência de diferentes fatores que interferem na implementação e aplicação da SAE. Alguns desses fatores estão no âmbito da organização (como, por exemplo, a maneira como o processo tem sido operacionalizado, muitas vezes com imposição da chefia de enfermagem, falta de recursos materiais, estrutura precária); outros fazem parte do próprio quotidiano dos enfermeiros (atitudes, crenças, habilidades técnicas), para os quais muitas vezes são justificados na falta de conhecimento teórico e prático, no excesso de trabalho, etc. [3,12,15,18,20-22,24].

A falta de conhecimento suficiente e a falta de interesse e comprometimento dos profissionais de enfermagem constituem obstáculos relevantes à implantação da SAE nas instituiçóes de saúde, assim como a sua execução efetiva nas instituiçóes que já a adotam como metodologia assistencial [5,11,13,16,17,23-24].

Para implantar a SAE é de suma importância que haja capacitaçáo de todos os membros da equipe sobre o tema, pois o despreparo impede a adesão dos profissionais ao processo de implantação da SAE, levando-os a realizá-la apenas para atender as normas estabelecidas pela instituição [26].

Conforme apontam Takahashi et al. [19], quando os enfermeiros realizam o processo de enfer- 
magem sem o devido conhecimento, "o fazem apenas para o cumprimento de tarefa institucional, não havendo a conscientização coletiva da importância deste processo para a sua atuação como profissional da saúde com responsabilidade social."

Alguns artigos constataram que embora as etapas da SAE tenham sido ministradas durante a graduação, os enfermeiros encontram dificuldades na sua aplicação prática $[12,13,16,17,19,23,26]$. Essa situaçáo pode decorrer da dicotomia entre o ensino da teoria e a prática de trabalho no serviço, que muitas vezes náo conta com a SAE implantada como metodologia assistencial, gerando insegurança e descrédito entre os estudantes e dificultando o desempenho didático [14].

A etapa da SAE que parece provocar maiores dificuldades é o diagnóstico de enfermagem $[17,21,23]$. Essa dificuldade decorre da forma como o ensino dessa temática vem sendo conduzido, muitas vezes sem oportunizar ao aluno formas de pensar, refletir e tomar decisóes sobre determinados problemas [16].

Confirmando esse entendimento, no estudo de Takahashi et al. [19], os enfermeiros participantes apontaram a insuficiência de conhecimentos teóricos básicos e específicos sobre a taxonomia diagnóstica para a sua aplicação na prática como uma das causas dessa dificuldade. Os principais motivos citados pelas enfermeiras estáo relacionados ao tempo para se buscar a definição estabelecida pela NANDA (American Nursing Diagnosis Association), fazendo com que essa procura fosse referida pelos profissionais como perda de tempo e a relação de dependência com o diagnóstico médico.

A fase do levantamento dos diagnósticos de enfermagem tem sua utilização na prática ainda dificultada [21]. Os enfermeiros apontam dificuldades em elaborar diagnósticos de enfermagem por considerarem o assunto muito complexo, desconhecerem o tema, considerarem que as taxonomias utilizadas não representam a realidade brasileira, por terem receio da responsabilidade exigida para a elaboração dos mesmos e por existir resistência por parte dos profissionais médicos e inclusive dos enfermeiros quanto à utilização de diagnóstico como ferramenta de trabalho da enfermagem.

França et al. [16] advertem que "a supressão ou formulação incorreta do diagnóstico pode comprometer todas as demais fases do processo de enfermagem."

Outro fator apontado como um desafio à implantação da SAE é a resistência à aceitação de mudanças nas rotinas da prática profissional, além da descrença do enfermeiro quanto às mudanças ao novo sistema e a falta de adesão de todos os envolvidos [3,15,20,22-24].

Sobre este aspecto, torna-se necessária a sensibilização dos profissionais por parte da chefia de enfermagem sobre a importância dessa metodologia para que todos se sintam motivados a implementá-la. Backes e Schwartz [5] sugerem a realização de estudos práticos, seminários de sensibilização e conscientização individual e grupal e no desenvolvimento de dinâmicas coletivas, de forma a levar a enfermagem a refletir sobre as condiçóes de trabalho e o seu modo de agir, de maneira crítica e consciente.

Outros fatores apontados como dificultadores na realização da SAE foram: falta de tempo, sobrecarga de trabalho, número insuficiente de profissionais, desvios de função, inadequação do instrumento [3,5,11-14,15,18-20,22-24].

Estas dificuldades são de ordem estrutural e demandam algumas reflexóes, posto ser os recursos humanos um dos fatores mais relevantes na operacionalização da SAE, seja no aspecto quantiqualitativo, seja no que se refere à função de cada membro da equipe.

O déficit de recursos humanos acarreta, muitas vezes, dificuldades no pensar estratégico necessário à implantação da SAE, bem como operacionalmente na aplicação das fases do processo de enfermagem, principalmente, no que concerne à falta de tempo [24]. Para os autores, a coleta de dados é a fase mais comprometida com a insuficiência de recursos humanos, podendo interferir negativamente nas fases subsequentes, posto que do bom histórico deriva o levantamento dos problemas, ou seja, os diagnósticos de enfermagem, para então o planejamento das ações e implementação das mesmas.

O número reduzido de funcionários e ausência de enfermeiros nas 24 horas dificulta também a operacionalização da SAE [21]. A esse respeito, Hermida e Araújo [26] questionam se as instituições de saúde brasileiras estão preparadas e interessadas em aumentar seu quadro de enfermagem em quantidade suficiente que garanta a implantação efetiva dessa metodologia.

Destaca-se o fato de que os enfermeiros desempenham vários papéis no trabalho cotidiano, ora atuando na implementação da SAE e na prática assistencial, exercendo atividades educacionais frente à sua equipe e ao paciente, ora no gerenciamento 
de unidades hospitalares com visão estratégica, conciliando seus conhecimentos técnico científicos com habilidades de relacionamento interpessoal e estabelecendo prioridades e organização [14].

Em estudo realizado em 2005 [14], observou-se que a atuaçáo do enfermeiro nem sempre está direcionada ao atendimento das necessidades do cliente, e sim à realização de açôes não inerentes à enfermagem, levando à execução de atividades de outros profissionais ou cumprimento de tarefas puramente burocráticas, o que desvia o enfermeiro do cumprimento de suas atribuiçôes.

Os desvios de função e a sobrecarga de trabalho da enfermagem deparam-se com o número deficitário de enfermeiros em relação à taxa de ocupação de leitos, que é uma realidade em muitas instituiçóes de saúde, o que colabora para potencializar o acúmulo de atribuiçóes desse profissional [14,27].

Associados a estes fatores, acrescenta-se o fato de que dentre as atividades desempenhadas pelos enfermeiros encontram-se aquelas envolvendo registros, anotações, relatórios e comunicações, utilizando grande parte de seu tempo em atividades burocráticas e na busca e documentação das informaçóes. Estudos estimam que os enfermeiros despendam até $40 \%$ de seu tempo coletando, administrando e documentando informaçóes [27].

Para reduzir o tempo de implementação das etapas da SAE, Rezende e Gaizinski [28] sugerem a implementação de um sistema de padronização de linguagem, possibilitando, assim, um maior tempo para o cuidado direto ao paciente. Sperandio e Évora [27] elaboraram um software capaz de sistematizar açóes individuais a cada paciente, na tentativa de otimizar o tempo e compartilhar as informaçóes entre toda a equipe, reduzindo a distância entre administrar e cuidar.

As dificuldades apontadas no contexto da prática assistencial refletem negativamente na forma adotada pelos enfermeiros em realizar a sistematização: mecanizada, repetitiva e náo respeitando a individualidade do paciente [20].

\section{Conclusão}

A Sistematização da Assistência de Enfermagem é uma ferramenta essencial no trabalho do enfermeiro, que proporciona um atendimento de qualidade ao paciente-cliente. Contudo, apesar de sua implantação ser, nos termos da legislação profissional, uma exigência legal, existem diversos fatores que são apontados como obstáculos que dificultam a sua aplicação nas instituições de saúde, como se pode constatar nos artigos analisados, tais como: falta de conhecimento teórico sobre o processo de enfermagem, sobre a realizaçáo de exame físico e prescrição de enfermagem, sobrecarga de trabalho, insuficiência de recursos humanos, falta de tempo, falta de motivação e comprometimento, resistência a mudanças e falta de credibilidade nas prescriçóes de enfermagem.

Conhecer tais dificuldades torna-se importante para orientar os profissionais envolvidos na superação desses empecilhos, sendo papel do enfermeiro identificar tais fatores e trabalhar no sentido de solucioná-los, possibilitando, dessa forma, a implantaçáo da SAE.

Além disso, é fundamental que o papel da enfermagem seja reconhecido pelas instituiçóes de saúde e que os profissionais sejam atualizados continuamente através de um programa de educação continuada em serviço.

\section{Referências}

1. Truppel TC, Meier MJ, Calixto RC, Peruzzo AS, Crozeta K. Sistematização da assistência de enfermagem em unidade de terapia intensiva. Rev Bras Enferm 2009;62(2):221-7.

2. Silva DCN, Ribeiro AA, Fabrício SCC. Produção do conhecimento sobre sistematização da assistência de enfermagem a idosos. Rev Enferm UERJ 2007;15(3):406-410.

3. Backes DS, Esperança MP, Amaro AM, Campos IEF, Cunha AD, Schwartz E. Sistematização da assistência de enfermagem: percepção dos enfermeiros de um hospital filantrópico. Acta Sci Health Sci 2005;27(1):25-9.

4. Cunha SMB, Barros ALBL. Análise da implementação da sistematização da assistência de enfermagem, segundo o modelo conceitual de Horta. Rev Bras Enferm 2005;58(5):568-72.

5. Backes DS, Schwartz E. Implementação da sistematização da assistência de enfermagem: desafios e conquistas do ponto de vista gerencial. Ciênc Cuid Saúde 2005;4(2):182-8.

6. Figueiredo RM, Zem-Mascarenhas SH, Napoleão AA, Camargo AB. Caracterização da produção do conhecimento sobre sistematização da assistência de enfermagem no Brasil. Rev Esc Enferm USP 2006;40(2):299-303.

7. Conselho Federal de Enfermagem (COFEN). Resolução COFEN no 358 de 15 de outubro de 2009. Dispóe sobre a Sistematização da Assistência de Enfermagem e a implementaçáo do Processo de Enfermagem em ambientes, públicos ou privados, em que ocorre o cuidado profissional de Enfermagem. Rio de Janeiro: Cofen; 2009.

8. Lei $n^{\circ} 7.498$, de 25 de Junho de 1986. Dispóe sobre a 
regulamentação do exercício da enfermagem e dá outras providências. Brasília: Diário Oficial da República Federativa do Brasil; 1986.

9. Horta WA. Processo de enfermagem. São Paulo: EPU; 1979.

10. Rother ET. Revisão sistemática X revisão narrativa. Acta Paul Enferm 2007;20(2):5-6.

11. Monte ADAS, Adami NP, Barros ALBL. Métodos avaliativos da assistência de enfermagem nas instituiçóes hospitalares. Acta Paul Enferm 2001;14(1):89-97.

12. Hermida PMV. Desvelando a implementação da sistematização da assistência de enfermagem. Rev Bras Enfermagem 2004;57(6):733-37.

13. Pivotto F, Lunardi Filho WD, Lunardi VL. Prescrição de enfermagem: dos motivos da não realização às possíveis estratégias de implementação. Cogitare Enferm 2004;9(2):32-42.

14. Andrade JS, Vieira MJ. Prática assistencial de enfermagem: problemas, perspectivas e necessidade de sistematização. Rev Bras Enferm 2005;58(3):261-5.

15. Reppetto MA, Souza MF. Avaliação da realizaçáo e do registro da Sistematização da Assistência de enfermagem (SAE) em um hospital universitário. Rev Bras Enfermagem 2005;58(3):325-9.

16. França FCV, Kawaguchi IAL, Silva EP, Abrão, GA, Uemura H, Alfonso LM, Carvalho EO. Implementaçáo do diagnóstico de enfermagem na unidade de terapia intensiva e os dificultadores para enfermagem - relato de experiência. Rev Eletrônica Enferm 2007;9(2):53746.

17. Gonçalves LRR, Nery IN, Nogueira LT, Bonfim EG. O desafio de implantar a sistematização da assistência de enfermagem sob a ótica de discentes. Esc Anna Nery Rev Enferm 2007;11(3):459-65.

18. Vargas RS, França FCV. Processo de Enfermagem aplicado a um portador de Cirrose Hepática utilizando as terminologias padronizadas NANDA, NIC e NOC.
Rev Bras Enfermagem 2007;60(3):348-52.

19. Takahashi AA, Barros ALBL, Michel JLM, Souza MF. Dificuldades e facilidades apontadas por enfermeiras de um hospital de ensino na execução do processo de enfermagem. Acta Paul Enferm 2008;21(1): 32-8.

20. Felix NN, Rodrigues CDS, Oliveira VDC. Desafios encontrados na realização da Sistematização da Assistência de Enfermagem (SAE) em unidade de pronto atendimento. Arq Ciênc Saúde 2009;16(4):155-60.

21. Tannure MC, Ferreira FKS, Costa CAB, Jorge CP, Viana GES, Teixeira LC et al. Fatores que dificultam a implantaçáo do processo de enfermagem na prática profissional. Nursing 2009;12(138):517-9.

22. Luiz FF, Mello SMM, Neves ET, Ribeiro AC, Tronco CS. A sistematização da assistência de enfermagem na perspectiva da equipe de um hospital de ensino. Rev Eletrônica Enferm 2010;12(4):655-59.

23. Remizoski J, Rocha MM, Vall J. Dificuldades na implantação da sistematização da assistência de enfermagem - SAE: uma revisão teórica. Cadernos da Escola de Saúde 2010;3:1-14.

24. Silva MM, Moreira MC. Desafios à sistematização da assistência de enfermagem em cuidados paliativos oncológicos: uma perspectiva da complexidade. Rev Eletrônica Enferm 2010;12(3):483-90.

25. Bittar DB, Pereira LV, Lemos RCA. Sistematização da assistência de enfermagem ao paciente crítico: proposta de instrumento de coleta de dados. Texto \& Contexto Enfermagem 2006;15(4):617-28.

26. Hermida PMV, Araújo IEM. Sistematização da Assistência de Enfermagem: subsídios para implantação. Rev Bras Enferm 2006;59(5):675-9.

27. Sperandio DJ, Evora YDM. Planejamento da assistência de enfermagem: proposta de um software-protótipo. Rev Latinoam Enferm 2005;13(6):937-43.

28. Rezende PO, Gaizinski RR. Tempo despendido no sistema de assistência de enfermagem após implementação de sistema padronizado de linguagem. Rev Esc Enferm USP 2008;42(1):152-9. 